\title{
Produção agroeconômica de três variedades de alface: cultivo com e sem amontoa ${ }^{1}$
}

\author{
Agro-economic yield of three varieties of lettuce, cultivated with and without hilling
}

\author{
Néstor Antonio Heredia Zárate ${ }^{2 *}$, Maria do Carmo Vieira ${ }^{3}$, Marcelo Helmich ${ }^{4}$, Diego Menani Heid e Carlos $^{5}$ \\ Tutida Menegati ${ }^{5}$
}

\begin{abstract}
Resumo - O objetivo do trabalho foi avaliar o comportamento produtivo e a sustentabilidade de três variedades de alface (Cinderella - tipo crespa, Rafaela - tipo americana e Elisabeth - tipo lisa), cultivadas com e sem amontoa, nas condições ambientes de Dourados-MS. Os tratamentos foram arranjados como fatorial 3 x 2, no delineamento experimental de blocos casualizados, com cinco repetições. Aos 77 dias após a semeadura fez-se a colheita. O número e a altura e o diâmetro das "cabeças" de alface, assim como as massas frescas de "cabeças" comerciais e não comerciais, foram influenciados significativamente pela interação das variedades e do cultivo com e sem amontoa. A alface Rafaela apresentou as maiores produções, sob amontoa, exceto para número de "cabeças" não comerciais que foi menor e inversamente relacionada com o número de "cabeças" comerciais. Os custos de produção das alfaces cultivadas, com e sem amontoa, foram de R $\$ 4.936,99$ ha $^{-1}$ e $\mathrm{R} \$ 4.467,06$ ha $^{-1}$, respectivamente. Nas condições em que foi desenvolvido o experimento, as maiores rendas líquidas ( $\mathrm{R} \$ 38.827,51 \mathrm{ha}^{-1}$ e $\mathrm{R} \$ 35.397,44 \mathrm{ha}^{-1}$, com e sem amontoa, respectivamente) foram obtidas com a alface Rafaela, em relação às alfaces Cinderella e Elisabeth, em qualquer uma das formas de cultivo estudadas. A amontoa induziu maiores rendas líquidas dentro de cada variedade de alface estudada. Concluiu-se que para se obter maior produção de "cabeças" de alface comerciais e maior renda líquida deve-se optar pelo cultivo da variedade Rafaela e utilizar a amontoa como trato cultural.
\end{abstract}

Palavras-chave - Alface. Plantas. Cultivares.

\begin{abstract}
The aim of this research was to evaluate the productive behavior of three varieties of lettuce (Cinderella - crisp type, Rafaela - American type and Elisabeth - looseleaf type), which were cultivated with and without hilling, in Dourados-MS environmental conditions. Treatments were arranged as $3 \times 2$ factorial scheme, in a randomized experimental block design, with five replications. On 77 days after sowing harvest was done. Number, height and diameter of lettuce "heads", as well fresh mass of commercial and non-commercial "heads" were influenced significantly by interaction of varieties and of cultivation with and without hilling. Rafaela lettuce showed the greatest yield, under hilling, except to number of non-commercial "heads", which were the smallest and related inversely with the number of commercial "heads". Yield costs of cultivated lettuce, with or without hilling, were $\mathrm{R} \$ 4,936.99 \mathrm{ha}^{-1}$ and $\mathrm{R} \$ 4,467.06 \mathrm{ha}^{-1}$, respectively. In the conditions that the experiment was carried out, the greatest net income ( $\mathrm{R} \$ 38,827.51 \mathrm{ha}^{-1}$ and $\mathrm{R} \$ 35,397.44 \mathrm{ha}^{-1}$, with and without hilling, respectively) were obtained with Rafaela lettuce, in relation to Cinderella and Elisabeth lettuces, in every studied ways of cultivation. The hilling induced greater net incomes in every studied variety of lettuce. It was concluded that in order to obtain the greatest yield of commercial lettuce "heads" and the greatest net income, it must opt by to cultivate Rafaela variety and to utilize of hilling as cultural treat.
\end{abstract}

Key words - Lettuce. Plant. Cultivars.

\footnotetext{
* Autor para correspondência

${ }^{1}$ Recebido para publicação em 05/03/2010; aprovado em 10/11/2010

Pesquisa financiada pela FUNDECT-MS e pelo CNPq

${ }^{2}$ Faculdade de Ciências Agrárias, Universidade Federal da Grande Dourados, Rua José Domingos Baldasso nº 72, Parque Alvorada, Dourados-MS, Brasil, 79.823-480, nahz@terra.com.br

${ }^{3}$ Faculdade de Ciências Agrárias, Universidade Federal da Grande Dourados, Caixa Postal 533, Dourados-MS, Brasil, 79.804-970, vieiracm@terra. com.br

${ }^{4}$ Mestrando em Agronomia, Universidade Federal da Grande Dourados, Av. Weimar Gonçalves Torres, 1128, ap. 03, Centro, Dourados-MS, Brasil, 79.800-020, marcelohelmich@hotmail.com

${ }^{5}$ Graduação do Curso de Agronomia, Universidade Federal da Grande Dourados. Rua Francisco Luiz Viegas, 1695, Jardim Guanabara, Dourados-MS, Brasil,79.831-390, diegoheid@hotmail.com,cmenegati@hotmail.com
} 


\section{Introdução}

Na produção de hortaliças, a preocupação com a sustentabilidade é fruto das reflexões da relação do homem com o ambiente. Apenas na década de 60, a humanidade começou a se dar conta de que o potencial de transformação desenvolvido pelo progresso tecnológico estava gerando problemas numa escala mais ampla do que a natureza podia corrigi-los. Assim, o desafio da sustentabilidade não se restringe a gerar soluções ambientalmente adequadas, mas também lucrativas e socialmente desejáveis (KHATOUNIAN, 1997). Por isso, em todas as atividades desenvolvidas pelo homem com fins de retorno econômico, onde a produção de hortaliças não foge a esta regra, a aplicação de tecnologias em diferentes níveis representa a diferença entre alta e baixa produtividade, refletindose na maior ou menor competitividade e rentabilidade (VILELA; MACEDO, 2000).

No Mato Grosso do Sul, somente nos últimos anos, vem aumentando a procura de espécies alternativas e sustentáveis, em especial aquelas que podem ser cultivadas em pequenas áreas, como é o caso das hortaliças. Esse fato é conseqüência da proliferação de chácaras e agrovilas, ao redor das maiores cidades do Estado, possibilitando assim a formação de cinturões verdes, com a venda de produtos diretamente aos supermercados e aos consumidores. Ampliam-se dessa forma as necessidades de pesquisas tecnológicas para as principais hortaliças comercializadas, dentre elas, alface, alho, beterraba, cenoura, cebola e milho-verde (HEREDIA ZÁRATE; VIEIRA, 2005a).

A alface (Lactuca sativa L.) é uma hortaliça popular no planeta, com elevado teor de vitamina A nas folhas verdes, alcançando até $4.000 \mathrm{UI} / 100 \mathrm{~g}$. Seu consumo tem aumentado cada dia, devido ao aumento exponencial da população e a mudanças no hábito alimentar do consumidor, na busca de alimentos mais saudáveis (FILGUEIRA, 2003). Tsuneshiro (2004), citado por Pimentel et al. (2009), relata que no Estado de São Paulo, no ano de 2003, a cultura de alface atingiu volume de comercialização de $\mathrm{R} \$ 25,2$ milhões. No Mato Grosso do Sul, em 1996, a área cultivada com alface foi de 203 ha e no município de Dourados, foi a hortaliça folhosa de maior área cultivada, com 65 ha (GRACIANO et al., 2007).

A produção de alface depende da interação genótipo e ambiente. A escolha criteriosa da cultivar é decisiva para o sucesso do sistema de cultivo adotado (ECHER et al., 2001). Isso porque, as plantas de cada cultivar respondem de maneira distinta aos fatores ambientais e às práticas agrícolas, dentre elas o espaçamento, que determina o número de plantas por unidade de área, alterando a produção, a massa e a qualidade das "cabeças" (SILVA et al., 2000). A alface é classificada comercialmente, segundo o Programa Horti \& Fruti Padrão da Secretaria de Agricultura e Abastecimento do Estado de São Paulo, em Americana, Crespa, Lisa, Mimosa e Romana. Desses tipos, o mais consumido é a alface Crespa (TRANI et al., 2005).

Dentre as operações relacionadas com tratos culturais, a amontoa é uma das mais tradicionais e tem como característica o "amontoamento ou chegamento" de terra ao "pé" da planta, sendo muito valorizada e considerada uma operação imprescindível para otimizar tecnologias e obtenção de altas produtividades (PECHE FILHO, 2008). As vantagens da amontoa são, dentre outras, cobrir adubos colocados em cobertura; eliminar plantas infestantes; formação de sulco que permita a distribuição mais localizada e em profundidade da água, evitando o contato direto com a planta, ou servindo para escoamento do excesso de água, da irrigação ou das chuvas; destruição de crosta superficial no solo que diminua ou impeça a infiltração lateral da água; induzir o aumento do sistema radicular absorvente; aumento da resistência ao tombamento e/ou à quebra dos caules e evitar a insolação direta nas raízes e caules comestíveis de algumas plantas. Dentre as desvantagens da amontoa têm-se: corte de raízes superficiais e laterais; formação de feridas nas raízes e/ou nos caules que permitam infecções e aumento do custo de produção da cultura (HEREDIA ZÁRATE; VIEIRA, 2005b).

A prática da amontoa tem sofrido questionamentos de sua real necessidade e época da realização por haver poucos resultados relacionados a esse estudo e por ser prática "corriqueira" em cultivos orgânicos (PUIATTI et al., 2005). Na bibliografia consultada, para alface não foram encontradas recomendações de amontoas, quanto à forma ou número.

Em razão do exposto, este trabalho teve como objetivo avaliar o comportamento produtivo e a sustentabilidade de três cultivares de alface, cultivadas com e sem amontoa, nas condições ambientes de Dourados-MS.

\section{Material e métodos}

O trabalho foi desenvolvido em área do Horto de Plantas Medicinais, da Universidade Federal da Grande Dourados, em Dourados MS, entre 13-6-2009 e 28-8-2009. O solo é classificado como Latossolo Vermelho Distroférrico, de textura muito argilosa, com as seguintes características de fertilidade: 6,0 de $\mathrm{pH}$ em água; 26,6 $\mathrm{g} \mathrm{dm}^{-3}$ de M.O; 31,0 $\mathrm{mg} \mathrm{dm}^{-3}$ de P; 6,$1 ; 46,6 ; 18,0 ; 110,7$ e 70,7 $\mathrm{mmol}_{\mathrm{c}} \mathrm{dm}^{-3}$ de $\mathrm{K}, \mathrm{Ca}, \mathrm{Mg}$, CTC e Soma de Bases, respectivamente, e $63,0 \%$ de Saturação de Bases. 
O experimento consistiu no estudo de três variedades de alface (Cinderella - tipo crespa, Rafaela - tipo americana e Elisabeth - tipo lisa), cultivadas com e sem amontoa. Os tratamentos foram arranjados como fatorial $3 \times 2$, no delineamento experimental de blocos casualizados, com cinco repetições. As parcelas tiveram área total de 3,0 $\mathrm{m}^{2}(1,5 \mathrm{~m}$ de largura $\mathrm{x}$ 2,0 $\mathrm{m}$ de comprimento) e área útil de $2,0 \mathrm{~m}^{2}(1,0 \mathrm{~m}$ de largura e 2,0 $\mathrm{m}$ de comprimento). Os espaçamentos entre plantas e entre fileiras, dentro de cada canteiro, foi de $0,25 \mathrm{~m}$, com população correspondente de 105.600 plantas ha ${ }^{-1}$.

O solo da área do experimento foi preparado com aração, gradagem e levantamento de canteiros com rotoencanteirador. Não foi realizada nenhuma adubação química, mas incorporou-se cama-de-frango semidecomposta em dose correspondente a $10 \mathrm{t} \mathrm{ha}^{-1}$. A cama-de-frango semidecomposta utilizada teve como base a casca de arroz e teve a seguinte composição: $\mathrm{C}_{\text {orgânico }}(\%)=29,12 ; \mathrm{P}_{\text {total }}(\%)=1,15 ; \mathrm{N}_{\text {total }}(\%)=1,75$; $\mathrm{K}_{\text {total }}(\%)=0,63 ; \mathrm{Ca}_{\text {total }}(\%)=3,58 ; \quad \mathrm{Mg}_{\text {total }}(\%)=0,69$ e relação $\mathrm{C} / \mathrm{N}=16,64$. A semeadura foi realizada diretamente no local definitivo, colocando-se quatro sementes por cova. Quando as plântulas atingiram cerca de $8 \mathrm{~cm}$ de altura, o que aconteceu aos 34 dias após a semeadura, foi realizado o desbaste, deixando-se uma planta por cova. As irrigações foram feitas por aspersão, diariamente, com o intuito de manter o solo com 70 a $75 \%$ da capacidade de campo, mediante observações visuais e utilizando-se o tato. O controle das plantas infestantes foi com auxílio de enxadas nas entrelinhas e com a retirada manual dentro das linhas. Não houve incidência de pragas e/ou doenças. A amontoa foi realizada aos 46 dias após a semeadura pela movimentação de terra desde as entrelinhas até a base das plantas, encobrindose os caules até cerca de $2 \mathrm{~cm}$ acima do coleto.

Aos 77 dias após a semeadura considerou-se que as alfaces estavam em fase de colheita, utilizando-se como indicativo do ponto de colheita o início de alongamento dos caules, o que antecede o pendoamento (VIEIRA et al., 2003). As plantas foram cortadas no caule, rente ao solo e embaladas em sacos de PVC, para condução até ao Laboratório de póscolheita onde foram classificadas em comerciais (diâmetro apical das cabeças, superiores a $20 \mathrm{~cm}$ ) e não-comerciais (diâmetro apical das cabeças, inferiores a $20 \mathrm{~cm}$ ). Depois, foram medidas a altura e o diâmetro apical das "cabeças" das plantas, utilizando régua graduada em centímetros. Posteriormente, foram determinados os números e as massas frescas (pesagem em balança digital, com resolução de $0,01 \mathrm{~g}$ ) de cada tipo. Para a obtenção da massa seca, os materiais frescos foram seccionados e distribuídos em sacos de papel previamente identificados. Posteriormente, os sacos foram colocados em estufa com circulação forçada de ar, a $60 \pm 5{ }^{\circ} \mathrm{C}$, até massa constante. Os valores obtidos foram transformados em $\mathrm{t} \mathrm{ha}^{-1}$.
Os dados foram submetidos à análise de variância e quando verificou-se significância pelo teste F, utilizou-se o teste de Tukey, a 5\% de probabilidade.

A sustentabilidade ou renda líquida foi determinada pela renda bruta por hectare cultivado menos os custos de produção. Para isso, foram pesquisados os preços (R\$ 0,65 por "cabeça") pagos aos produtores de alface, dos arredores de Dourados, e posteriormente efetuaram-se as conversões por hectare, pela multiplicação do número de "cabeças" comerciais ha- correspondente a cada tratamento pelo preço por "cabeça". Os custos de produção foram calculados usando como referência tabela adaptada de Terra et al. (2006).

\section{Resultados e discussão}

\section{a. Agronômica}

O número, a altura e o diâmetro das "cabeças" da alface, comerciais e não-comerciais, foram influenciados significativamente pela interação das variedades e do cultivo com e sem amontoa (TAB. 1). A maior influência foi observada na variedade Rafaela, que apresentou os melhores resultados, sendo que os maiores valores para as características avaliadas foram nas plantas cultivadas com amontoa, exceto para número de "cabeças" não-comerciais que foi menor e inversamente relacionado com o número de "cabeças" comerciais (TAB. 2). Isso indica que houve respostas modificativas que adaptaram as plantas às condições ambientes, durante o seu período de crescimento (LARCHER, 2006) em função da capacidade suporte do meio e do sistema de produção adotado em conformidade com as características genotípicas (HARDER et al., 2005).

Os resultados obtidos neste experimento, em que as maiores cabeças de alface apresentaram diâmetros entre $22,28 \mathrm{~cm}$, no tratamento sem amontoa e 23,97 cm, no tratamento com amontoa e que relacionaram-se diretamente com os maiores números por hectare, 61.330 plantas ha ${ }^{-1}$ e 67.330 plantas ha-1, respectivamente, que foi o caso da variedade Rafaela, discordam com o relatado por Varo-Vicedo et al. (1999) quando citam que o tamanho das "cabeças" de alface é inversamente proporcional ao número de plantas por metro quadrado, como verificaram, nos seus resultados, em que a maior massa média de cabeças de alface foi obtida sob a menor densidade de plantio (16,8 plantas $\left.\mathrm{m}^{-2}\right)$. Essas diferenças de expressividade indicam que as plantas podem apresentar taxas variáveis de crescimento e morfologia bem características, com modificações no final do ciclo vegetativo, em razão de fatores ambientais, especialmente de temperatura e luminosidade, nos locais onde foram cultivadas as plantas de alface. 
Tabela 1 - Resumo das análises de variância para número e altura e diâmetro das "cabeças" de alface, comerciais e não comerciais, de três variedades cultivadas com e sem amontoa. UFGD, Dourados, MS, 2009

\begin{tabular}{|c|c|c|c|c|c|c|c|}
\hline \multirow{3}{*}{ Fonte de Variação } & \multirow{3}{*}{ G.L. } & \multicolumn{6}{|c|}{ Quadrado médio } \\
\hline & & \multicolumn{3}{|c|}{ "Cabeças" comerciais } & \multicolumn{3}{|c|}{ "Cabeças" não-comerciais } \\
\hline & & Número & Altura & Diâmetro & Número & Altura & Diâmetro \\
\hline Repetições & 4 & $915,35^{* *}$ & $4,82 * *$ & $29,52 * *$ & $875,6^{* *}$ & $10,92 * *$ & $28,27 * *$ \\
\hline Cultivares (C) & 2 & $701,64 * *$ & $0,23^{\mathrm{ns}}$ & $11,17 * *$ & $542,47 * *$ & $2,81 * *$ & $0,97^{\mathrm{ns}}$ \\
\hline Amontoas (A) & 1 & $403,18^{* *}$ & $0,93 *$ & $1,05^{\mathrm{ns}}$ & $213,44^{*}$ & $4,37 * *$ & $3,84^{\mathrm{ns}}$ \\
\hline $\mathrm{C} \times \mathrm{A}$ & 2 & $193,27 *$ & $1,58 * *$ & $5,31 *$ & $103,34^{*}$ & $1,37^{*}$ & $4,84^{*}$ \\
\hline Resíduo & 20 & 49,13 & 0,17 & 1,28 & 28,46 & 0,26 & 0,92 \\
\hline Média & & 54,11 & 17,41 & 21,91 & 50,89 & 13,77 & 12,96 \\
\hline C.V. & & 12,95 & 2,36 & 5,16 & 10,48 & 3,67 & 7,40 \\
\hline
\end{tabular}

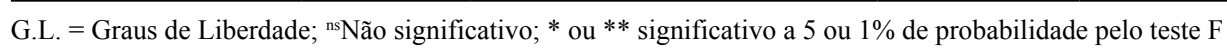

Tabela 2 - Número e altura e diâmetro das "cabeças" de alface, comerciais e não comerciais, de três variedades cultivadas com e sem amontoa. UFGD, Dourados, MS, 2009

\begin{tabular}{|c|c|c|c|c|c|c|c|}
\hline \multirow[b]{2}{*}{ Variedade } & \multirow[b]{2}{*}{ Amontoa } & \multicolumn{3}{|c|}{ "Cabeças" comerciais } & \multicolumn{3}{|c|}{ "Cabeças" não-comerciais } \\
\hline & & $\begin{array}{l}\text { Número } \\
\left(\mathrm{mil} \mathrm{ha}^{-1}\right)\end{array}$ & Altura $(\mathrm{cm})$ & $\begin{array}{l}\text { Diâmetro } \\
(\mathrm{cm})\end{array}$ & $\begin{array}{l}\text { Número } \\
\left(\mathrm{mil} \mathrm{ha}^{-1}\right)\end{array}$ & Altura $(\mathrm{cm})$ & $\begin{array}{c}\text { Diâmetro } \\
(\mathrm{cm})\end{array}$ \\
\hline \multirow{2}{*}{ Cinderella } & Com & $51,33 a$ & $17,65 \mathrm{a}$ & $20,80 \mathrm{a}$ & $54,00 \mathrm{a}$ & $13,60 \mathrm{a}$ & $12,74 \mathrm{a}$ \\
\hline & Sem & $49,33 a$ & $17,26 \mathrm{a}$ & $21,74 \mathrm{a}$ & $54,67 \mathrm{a}$ & $11,39 \mathrm{~b}$ & $13,52 \mathrm{a}$ \\
\hline \multirow{2}{*}{ Rafaela } & Com & $67,33 a$ & $17,80 \mathrm{a}$ & $23,97 \mathrm{a}$ & $38,67 \mathrm{~b}$ & $12,52 \mathrm{a}$ & $14,13 a$ \\
\hline & Sem & $61,33 \mathrm{~b}$ & $16,67 \mathrm{~b}$ & $22,28 \mathrm{~b}$ & $45,33 \mathrm{a}$ & $11,00 \mathrm{~b}$ & $12,17 \mathrm{~b}$ \\
\hline \multirow{2}{*}{ Elisabeth } & Com & $54,66 \mathrm{a}$ & $17,30 \mathrm{a}$ & $21,50 \mathrm{a}$ & $52,00 \mathrm{~b}$ & $11,52 \mathrm{a}$ & $13,08 \mathrm{a}$ \\
\hline & Sem & $40,67 \mathrm{~b}$ & $17,76 \mathrm{a}$ & $21,14 \mathrm{a}$ & $60,67 \mathrm{a}$ & $10,68 \mathrm{a}$ & $12,12 \mathrm{a}$ \\
\hline \multicolumn{2}{|c|}{ C.V. (\%) } & 12,95 & 2,36 & 5,16 & 10,48 & $3,67 \mathrm{~b}$ & 7,40 \\
\hline
\end{tabular}

Médias seguidas pela mesma letra, nas colunas, dentro de cada variedade, não diferem entre si pelo teste de Tukey, a $5 \%$ de probabilidade

Os valores obtidos neste trabalho, para altura e diâmetro das "cabeças" das três variedades de alface, foram superiores aos relatados por Oliveira et al. (2007), que em Mossoró-RN, entre outubro e dezembro de 2002 , estudaram as cultivares Elba $(12,48 \mathrm{~cm}$ de altura e $16,31 \mathrm{~cm}$ de diâmetro) e Tainá $(11,68 \mathrm{~cm}$ de altura e $18,60 \mathrm{~cm}$ de diâmetro) sob $0 ; 60 ; 80$ e $100 \mathrm{Mg} \mathrm{ha}^{-1}$ de cama-de-frango. Essa discordância dos resultados mostra relação com a diferença entre variedades de alface e com a diferença de condições ambientes dos locais de trabalho porque a capacidade produtiva das culturas está associada aos fatores genéticos da planta, à capacidade suporte do solo em água, nutrientes e aeração, à interação entre fatores bióticos, climáticos, edáficos e práticas de condução (SILVA et al., 2008).
As massas frescas de "cabeças" de alface comerciais e as massas fresca e secas das não-comerciais foram influenciadas significativamente pela interação das variedades e do cultivo com e sem amontoa. A massa seca das "cabeças" de alface comerciais não foram influenciados pelos fatores em estudo (TAB. 3). A maior influência foi observada na variedade Rafaela, sendo os maiores valores nas plantas cultivadas com amontoa (TAB. 4). Esse trato cultural deve ter colaborado na destruição da crosta superficial no solo que diminui ou impede a infiltração lateral da água e, com isso, deve ter havido aumento da quantidade de água e de nutrientes para o sistema radicular mais profundo, devido à formação de um sulco entre as fileiras de plantas, como efeito da amontoa. 
Tabela 3 - Resumo das análises de variância para massas fresca e seca de "cabeças" de alface, comerciais e não comerciais, de três variedades cultivadas com e sem amontoa. UFGD, Dourados, MS, 2009

\begin{tabular}{cccccc}
\hline \multirow{2}{*}{ Fonte de Variação } & \multirow{2}{*}{ G.L. } & \multicolumn{4}{c}{ Quadrado médio } \\
\cline { 3 - 6 } & & "Cabeças" comerciais & \multicolumn{2}{c}{ "Cabeças" não-comerciais } \\
\cline { 3 - 6 } & 4 & $15,98^{* *}$ & $0,11^{\text {ns }}$ & $1,68^{* *}$ & $0,011^{* *}$ \\
\hline Repetições & 2 & $59,83^{* *}$ & $0,18^{\text {ns }}$ & $1,32^{* *}$ & $0,004^{* *}$ \\
Cultivares (C) & $1,52^{\text {ns }}$ & $0,00^{\text {ns }}$ & $0,02^{\text {ns }}$ & $0,003^{*}$ \\
Amontoas (A) & 1 & $3,13^{* *}$ & $0,01^{\text {ns }}$ & $0,66^{* *}$ & $0,004^{* *}$ \\
C x A & 2 & 0,46 & 0,04 & 0,09 & 0,00065 \\
Resíduo & 20 & 4,79 & 0,37 & 1,65 & 0,14 \\
\hline Média & & 14,09 & 15,99 & 17,77 & 18,21 \\
\hline C.V. & & &
\end{tabular}

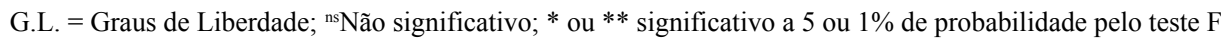

Tabela 4 - Massas frescas e secas de "cabeças" de alface, comerciais e não-comerciais, de três variedades cultivadas com e sem amontoa. UFGD, Dourados, MS, 2009

\begin{tabular}{|c|c|c|c|c|c|}
\hline \multirow[b]{2}{*}{ Variedade } & \multirow[b]{2}{*}{ Amontoa } & \multicolumn{2}{|c|}{ "Cabeças" comerciais } & \multicolumn{2}{|c|}{ "Cabeças" não-comerciais } \\
\hline & & $\begin{array}{l}\text { Massa fresca } \\
\left(\mathrm{Mg} \mathrm{ha}^{-1}\right)\end{array}$ & $\begin{array}{l}\text { Massa seca } \\
\left(\mathrm{Mg} \mathrm{ha}^{-1}\right)\end{array}$ & $\begin{array}{l}\text { Massa fresca } \\
\left(\mathrm{Mg} \mathrm{ha}^{-1}\right)\end{array}$ & $\begin{array}{l}\text { Massa seca } \\
\left(\mathrm{Mg} \mathrm{ha}^{-1}\right)\end{array}$ \\
\hline \multirow{2}{*}{ Cinderella } & Com & $3,31 \mathrm{a}$ & $(0,28)^{*}$ & $1,35 \mathrm{a}$ & $0,12 \mathrm{a}$ \\
\hline & Sem & $3,76 \mathrm{a}$ & $(0,33)$ & $1,44 \mathrm{a}$ & $0,13 \mathrm{a}$ \\
\hline \multirow{2}{*}{ Rafaela } & Com & $8,46 a$ & $(0,55)$ & $2,31 \mathrm{a}$ & $0,17 \mathrm{a}$ \\
\hline & Sem & $6,76 \mathrm{~b}$ & $(0,49)$ & $1,82 \mathrm{~b}$ & $0,16 \mathrm{a}$ \\
\hline \multirow{2}{*}{ Elisabeth } & Com & $3,28 \mathrm{a}$ & $(0,27)$ & $1,22 b$ & $0,11 \mathrm{~b}$ \\
\hline & Sem & $3,17 \mathrm{a}$ & $(0,28)$ & $1,76 \mathrm{a}$ & $0,17 \mathrm{a}$ \\
\hline \multicolumn{2}{|c|}{ C.V. (\%) } & 14,09 & 15,99 & 17,77 & 18,21 \\
\hline
\end{tabular}

Médias seguidas pela mesma letra, nas colunas, dentro de cada variedade, não diferem entre si pelo teste de Tukey, a $5 \%$ de probabilidade; * Médias entre parêntese foram não significativas

As massas frescas e secas das "cabeças" nãocomerciais da variedade Elisabeth foram maiores quando cultivadas sem amontoa e as comerciais foram semelhantes estatisticamente, tal como na Cinderella (TAB. 4). Esses resultados divergentes encontrados entre as variedades em estudo mostram que houve diferenças na provável capacidade de auto-regulação das plantas em relação ao equilíbrio das relações de interferência (LARCHER, 2006). Santos (1998) relata que as espécies podem apresentar mecanismos de compensação da produtividade, que podem ocorrer em função de modificações das suas populações nas associações e nos arranjos espaciais, ou mesmo em função do sincronismo de plantio e do desenvolvimento temporal delas. Freitas et al. (2007) citam que, entre os métodos propostos para o estudo da interação genótipo $\mathrm{x}$ ambiente, existem aqueles voltados para a regionalização de locais, e outros para o estudo da estabilidade de cultivares.

\section{b. Econômica}

Considerando que a função de produção é a relação que indica a quantidade máxima que se pode obter de um produto, por unidade de tempo, a partir da utilização de uma determinada quantidade de fatores de produção e mediante a escolha do processo de produção mais adequado (PERES JÚNIOR et al., 2003) e que, no caso deste trabalho, foi impossível determinar a função de produção, devido ao impedimento para calcular o produto marginal do fator de produção variável (Pmg). Então, optou-se por uma forma de cálculo econômico sugerido por Terra et al. (2006), para milho doce, o que permitiu relacionar os fatores em estudo (produtivos) com os prováveis retornos (econômicos), isto é, o relacionamento direto dos custos de produção (TAB. 5) com a renda bruta (TAB. 6). 
Os custos de produção das variedades de alface cultivadas com e sem amontoa foram de R $\$ 4.936,99$ e R\$ 4.467,06, respectivamente. Desses custos, os custos variáveis representaram 80,64 e $80,67 \%$, respectivamente. Dos custos variáveis, os insumos representaram 12,34 e $13,72 \%$ e a mão-de-obra representou 71,58 e $68,51 \%$, respectivamente. Estes dados ressaltam a importância da cultura, como atividade geradora de emprego no meio rural, por meio do uso de sua mão-de-obra.

Os resultados obtidos para a renda líquida (TAB. 5) confirmaram a necessidade de se estudar economicamente a aplicabilidade de algumas técnicas agrícolas, especialmente relacionadas com o uso de variedades diferentes e a amontoa. Isto porque, nas condições em que foi desenvolvido o experimento, a alface Rafaela induziu a obtenção das maiores rendas líquidas em relação às alfaces Cinderella e Elisabeth, em qualquer uma das formas de cultivo estudadas. Mas, a variedade Elisabeth mostrou a maior diferença entre as rendas líquidas ( $\mathrm{R} \$ 8.623,57)$, dentro de cada variedade. No geral, a amontoa proporcionou maiores rendas líquidas dentro de cada variedade de alface estudada.

Tabela 5 - Custos de produção de um hectare de alface, com e sem amontoa. UFGD, Dourados, MS, 2009

\begin{tabular}{|c|c|c|c|c|}
\hline \multirow{3}{*}{ Custos Variáveis } & \multicolumn{4}{|c|}{ Amontoa } \\
\hline & \multicolumn{2}{|c|}{ 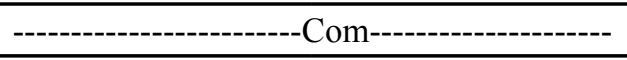 } & \multicolumn{2}{|c|}{---------------------Sem------------------ } \\
\hline & Quantidade & Custo (R\$) & Quantidade & Custo (R\$) \\
\hline \multicolumn{5}{|c|}{ Insumos } \\
\hline Semente & $0,53 \mathrm{~kg}$ & 95,40 & $0,53 \mathrm{~kg}$ & 95,40 \\
\hline Cama-de-frango-CF & $6,6 \mathrm{Mg}$ & 396,00 & $6,6 \mathrm{Mg}$ & 396,00 \\
\hline \multicolumn{5}{|c|}{ Mão-de-obra } \\
\hline Espalhar CF & $4,0 \mathrm{D} / \mathrm{H}$ & 100,00 & $4,0 \mathrm{D} / \mathrm{H}$ & 100,00 \\
\hline Semeadura & $6,0 \mathrm{D} / \mathrm{H}$ & 150,00 & $6,0 \mathrm{D} / \mathrm{H}$ & 150,00 \\
\hline Amontoa & $16,0 \mathrm{D} / \mathrm{H}$ & 400,00 & -- & -- \\
\hline Irrigação & $20,0 \mathrm{D} / \mathrm{H}$ & 500,00 & $20,0 \mathrm{D} / \mathrm{H}$ & 500,00 \\
\hline Capinas & $36,0 \mathrm{D} / \mathrm{H}$ & 900,00 & $36,0 \mathrm{D} / \mathrm{H}$ & 900,00 \\
\hline Colheita & $32,0 \mathrm{D} / \mathrm{H}$ & 800,00 & $32,0 \mathrm{D} / \mathrm{H}$ & 800,00 \\
\hline \multicolumn{5}{|c|}{ Maquinários } \\
\hline Bomba de irrigação & $40,0 \mathrm{~h}$ & 400,00 & $40,0 \mathrm{~h}$ & 400,00 \\
\hline Trator & $4,0 \mathrm{~h}$ & 240,00 & $4,0 \mathrm{~h}$ & 240,00 \\
\hline Subtotal $1(\mathrm{R} \$)$ & -- & $3.981,40$ & -- & $3.581,40$ \\
\hline \multicolumn{5}{|c|}{ Custos Fixos } \\
\hline Benfeitoria & 77,0 dias & 154,00 & 77,0 dias & 154,00 \\
\hline Terra & 1,0 ha & 100,00 & 1,0 ha & 100,00 \\
\hline Subtotal $2(\mathrm{R} \$)$ & -- & 254,00 & -- & 254,00 \\
\hline Imprevistos (10\% ST1) & -- & 398,14 & -- & 358,14 \\
\hline Administração (5\% ST1) & -- & 199,07 & -- & 179,07 \\
\hline Subtotal 3 & -- & 597,21 & -- & 537,21 \\
\hline TOTAL 1 & & $4.832,61$ & & $4.372,61$ \\
\hline Juro trimestral $(2,16 \%)$ & & 104,38 & & 94,45 \\
\hline TOTAL GERAL & & $4.936,99$ & & $4.467,06$ \\
\hline
\end{tabular}

Adaptado de Terra et al. (2006) 
Tabela 6 - Número e renda bruta de "cabeças" comerciais, custo de produção e renda líquida de três variedades de alface cultivadas com e sem amontoa. UFGD, Dourados, MS, 2009

\begin{tabular}{|c|c|c|c|c|c|}
\hline \multirow{2}{*}{ Variedade } & \multirow{2}{*}{ Amontoa } & \multicolumn{2}{|c|}{ "Cabeças" comerciais } & \multirow{2}{*}{$\begin{array}{l}\text { Custo de produção } \\
\left(\mathrm{R} \$ \mathrm{ha}^{-1}\right)\end{array}$} & \multirow{2}{*}{$\begin{array}{l}\text { Renda líquida } \\
\left(\mathrm{R} \$ \mathrm{ha}^{-1}\right)\end{array}$} \\
\hline & & Número $\left(\mathrm{mil} \mathrm{ha}^{-1}\right)$ & Renda bruta $\left(\mathrm{R} \$ \mathrm{ha}^{-1}\right)$ & & \\
\hline \multirow{2}{*}{ Cinderella } & Com & 51,33 & $33.364,50$ & $4.936,99$ & $28.427,51$ \\
\hline & Sem & 49,33 & $32.064,50$ & $4.467,06$ & $27.597,44$ \\
\hline \multirow{2}{*}{ Rafaela } & Com & 67,33 & $43.764,50$ & $4.936,99$ & $38.827,51$ \\
\hline & Sem & 61,33 & $39.864,50$ & $4.467,06$ & $35.397,44$ \\
\hline \multirow{2}{*}{ Elisabeth } & Com & 54,66 & $35.529,00$ & $4.936,99$ & $30.592,01$ \\
\hline & Sem & 40,67 & $26.435,50$ & $4.467,06$ & $21.968,44$ \\
\hline
\end{tabular}

\section{Conclusão}

Nas condições em que foi conduzido o experimento concluiu-se que para obter maior produção de "cabeças" de alface comerciais e maior renda líquida deve-se optar pelo cultivo da variedade Rafaela e utilizar a amontoa como trato cultural.

\section{Agradecimentos}

Ao $\mathrm{CNPq}$, pela concessão de bolsas de Produtividade em Pesquisa, de Mestrado e de Iniciação Científica e à FUNDECT-MS, pelos recursos financeiros.

\section{Referências}

ECHER, M. M. et al. Comportamento de cultivares de alface em função do espaçamento. Revista de Agricultura, v. 76, n. 02 , p. $267-275,2001$.

FILGUEIRA, F. A. R. Solanáceas: agrotecnologia moderna na produção de tomate, batata, pimentão, pimenta, berinjela e jiló. Lavras: UFLA, 2003. 333 p.

FREITAS, J. G. et al. Interação entre genótipo e ambiente em híbridos de melão Amarelo no Nordeste do Brasil. Revista Ciência Agronômica, v. 38, n. 02, p.176-181, 2007.

GRACIANO, J. D. et al. A. Produção e renda bruta de rabanete e alface em cultivo solteiro e consorciado. Acta Scientiarum. Agronomy, v. 29, n. 03, p. 397-401, 2007.

HARDER, W. C.; HEREDIA ZÁRATE, N. A.; VIEIRA, M. C. Produção e renda bruta de rúcula (Eruca sativa Mill.) 'Cultivada' e de almeirão (Cichorium intybus L.) 'Amarelo', em cultivo solteiro e consorciado. Ciência e Agrotecnologia, v. 29, n. 04, p. $775-785,2005$.

HEREDIA ZÁRATE, N. A.; VIEIRA, M. C. Produção da araruta 'Comum' proveniente de três tipos de propágulos. Ciência e Agrotecnologia, v. 29, n. 05, p. 995-1000, 2005a.
HEREDIA ZARATE, N. A.; VIEIRA, M. C. Hortas: conhecimento básicos. Dourados: UFMS. 2005b. 61 p.

KHATOUNIAN, C. A. A sustentabilidade e o cultivo de hortaliças. Horticultura Brasileira, v. 15, p. 199-205, 1997. Suplemento.

LARCHER, W. Ecofisiologia vegetal. São Carlos: RiMa Artes e Textos, 2006. $531 \mathrm{p}$.

OLIVEIRA, C. J. et al. Desempenho de cultivares de alface adubadas organicamente. Revista Verde, v. 02, n. 01, p. 160-166. 2007.

PECHE FILHO, A. Amontoa antecipada: Uma operação importante no sistema planta forte - batata. Disponível em: $<$ http://www.abbabatatabrasileira.com.br/revista10_019.htm> Acesso em: 15 de fev. 2008.

PEREZ JUNIOR, J. H.; OLIVEIRA, L. M.; COSTA, R. G. Gestão estratégica de custos. São Paulo: Atlas, 2003. 322 p.

PIMENTEL, M. S.; LANA, A. M. Q.; DE-POLLI H. Rendimentos agronômicos em consórcio de alface e cenoura adubadas com doses crescentes de composto orgânico. Revista Ciência Agronômica, v. 40, n. 01, p. 106 112, 2009.

PUIATTI, M. et al. Produção de Taro chinês em função de número de época e número de amontoa. In: CONGRESO BRASILEIRO DE OLERICULTURA, 45., 2005, Fortaleza. Resumos... Brasília, 2005. p. 76.

SANTOS, R. H. S. Interações interespecíficas em consórcio de olerícolas. 1998. 129 f. Tese (Doutorado em Fitotecnia), Universidade Federal de Viçosa, Viçosa.

SILVA, V. F. et al. Comportamento de cultivares de alface em diferentes espaçamentos sob temperatura e luminosidade elevadas. Horticultura Brasileira, v. 18, n. 03, p.183-187, 2000.

SILVA, F. P. et al. Desempenho produtivo de cultivares de ameixeira japonesa (Prunus salicina Lindl.), em Caldas-MG. Revista Ciência Agronômica, v. 39, n. 02, p. 281-286, 2008.

TERRA, E. R. et al. Proposta de cálculo e forma de adubação, com e sem amontoa, para a produção e renda do milho Superdoce 'Aruba'. Acta Scientiarum. Agronomy, v. 28, n. 01, p. 75-82, 2006. 
TRANI, P. E. et al. Alface (Lactuca sativa L.). Campinas: IAC, 2005. Disponível em: <http://www.iac.sp.gov.br/Tecnologias/ Alface/Alface.htm> Acesso em: 15 de fev. 2008.

VARO-VICEDO, P. et al. Ensayo de densidades de plantación en lechuga Little Gem 1998. In: AZNAR-SATORRE, J. M. et al. $\mathbf{2 8}^{\text {th }}$ Seminar of Technical and Specialists on Horticulture. Madrid: Ministério de Agricultura, Pesca y Alimentación, 1999. p. 157-159.
VIEIRA, M. C.; HEREDIA, ZÁRATE, N. A; BRATTI, R. Efeitos da cama-de-frangos e da época de colheita sobre a produção e a renda bruta da cebolinha 'Todo Ano'. Pesquisa Agropecuária Tropical, v. 33, n. 02, p. 73- 78, 2003.

VILELA, N. J.; MACEDO, M. M. C. Fluxo de poder no agronegócio: o caso das hortaliças. Horticultura Brasileira, v. 18, n. 02 , p. $88-94,2000$. 